\title{
Rediscovering the ARBs
}

\section{TERESA MAGUIRE}

\begin{abstract}
Teachers have so many assessment tools at their disposal today it can be overwhelming at times. In this article I will take you on a journey through the new-look Assessment Resource Banks website and show you some of the highlights I've discovered in the last few weeks back at NZCER. This tool is a valuable addition to anyone's kete.
\end{abstract}

When I left my teaching job at the end of 2015 I mentioned to a colleague that I was returning to the New Zealand Council for Educational Research (NZCER) after more than 7 years away. I would be helping to develop resources for the Assessment Resource Banks (ARBs). I casually asked her if she had used them with her students, to which she responded, "Not really, we already have enough assessment tools that we use-the PATs, e-asTTle and STAR — so we can't squeeze another one in to the mix." I didn't have a chance to stop and talk, but wished we could have discussed how much more there is to the ARBs than summative assessment. I would like to update her and other teachers on what I've learned in my first few weeks back on the job, immersing myself in the website and discovering all the exciting changes that have happened since I last helped develop resources.

\section{What are the ARBs?}

The ARBs are a collection of formative assessment resources in maths, English and science (you can find them at http://arbs.nzcer.org.nz). They have been developed by researcher-resource developers with experience in assessment, curriculum, teaching and learning. The resources are based on The New Zealand Curriculum (Ministry of Education, 2007), designed to be used in New Zealand classrooms and are free of charge. If you are a New Zealand educator all you need to do is register for a password.
In 2014 an article by Joyce and Fisher appeared in set which heralded the innovations that were about to happen in the ARBs. At the time the website was in its infancy. In the middle of last year the new website was launched and, wow, does it look different! The home page is clean, attractive, and simple, and behind it is an easily accessible treasure trove of nearly 3000 resources and an extensive range of support material for teachers. The resource developers have obviously been very busy while I've been teaching.

\section{Taking you on a tour of ARBs}

The new ARBs are easy to navigate and can be quickly personalised to your teaching needs and those of your students. When you conduct a search the list comes up with easy to read information-the level is clearly shown down the side, along with a brief description of the task and some keywords. Still not sure if it's the right resource for you? Click on the Preview button and a window pops up with a sneak peek of the resource. So it is now much easier than going back and forth between the search page results and the item. You can also refine your search results more than in the past to find just the right resource for your needs.

Have you noticed the little icons next to the items? They give you useful information about the resource. There's good old pencil and paper all the resources have, but there are also two others you 
will come across. This one lets you know that the resource is an online interactive resource and this one Q informs you that the item is completely auto-marked and will let the students know their results. I'll go into more detail about these types of resources later on in this article. Down the right-hand side are some red hearts with numbers beside them. These show how popular the resource is. You can "like" an individual resource once open by clicking on the little heart just near the resource title. Please do try it next time you find something that appeals to you-it will inform other teachers and resource developers alike.

Don't you hate it, though, when you find a great resource but when you go to show your colleagues or use it with a new class you can't locate it? Don't despair-My Folders are here. If you haven't used them before, it's even easier now because your personal login means that you don't have to deal with the multitude of folders that were created when there was a generic login and password. Now you have control over your ARB account and you can create and name your own folders, save items into them and manage them without interfering with other people's folders or losing your own. Just use "Save to My Folders" for a resource you may want to access again.

Once you have opened an assessment resource there is a wealth of ideas, advice, and links, now just a click away. It is easy to navigate to this information and, more importantly, easy to return to the resource with the "Overview" button. Another button, "Marking Student Responses", lets you quickly check the marking schedule, while the "Connecting to the Curriculum" button gives you information about the resource (level, keywords, task description) as well as links to the National Standards,



FIGURE 1. DESCRIBING BUTTERFLIES key competencies, the literacy learning progressions, and the science capabilities. Extra information about ways to administer the task or diagnostic information about common misconceptions can be found behind the buttons "Using this Resource" and "Working with Students'. As the ARBs are designed to be used formatively, this background information is invaluable as it allows teachers to use the resource in their classroom in the way that suits them best.

What if you wanted to find some more resources with a similar theme or that assessed the same content knowledge? Easy — either use the button "Further Resources" or, at the top right of the screen, click on "Find Similar".

\section{My favourite new online resources}

There are many different types of online resources. Here are some of the ones that stand out to me.

A great use of the online platform are the progressive disclosure items for English such as "What is Susan making?" or "What are 'they'?" In these resources students receive information verse by verse and integrate this with previous information to build up an understanding of the whole text. Another example is the maths assessment "What Shape Am I?". In this maths task a student is given an increasing number of clues which describe a shape and is asked to select which shape(s) fit the clues. The task culminates in the student having to provide their own clues for a shape of their choice and see if a peer can guess their shape from these clues. There is also a space for reflection on how well the description fits the shape.

Some of the new resources can only be used online. These resources really use the power of the online

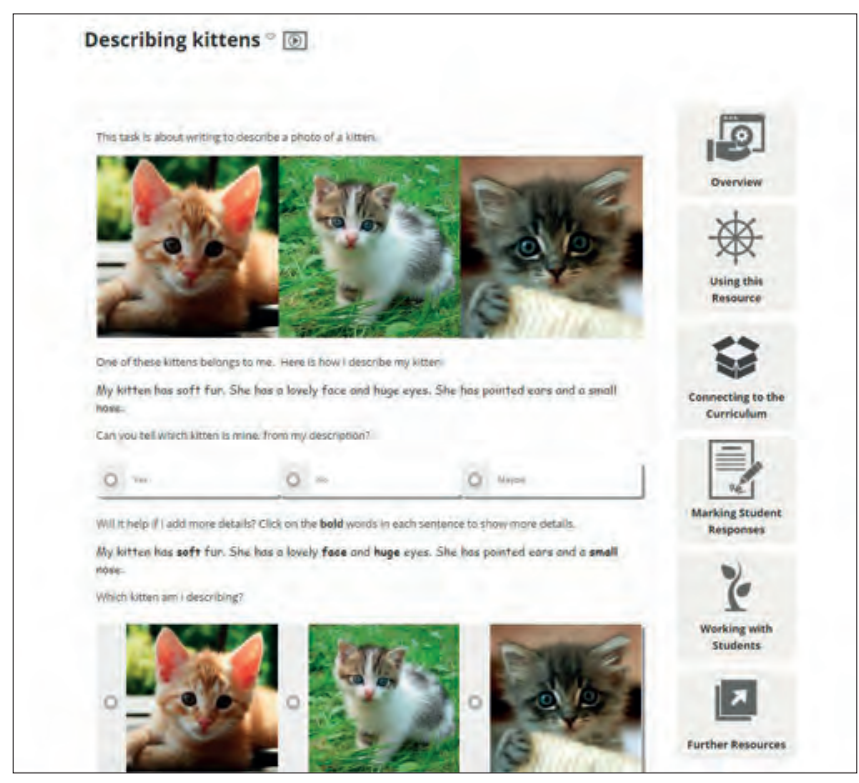

FIGURE 2. DESCRIBING KITTENS 
environment. For example, there is a wonderful set of descriptive writing tasks that start with kittens and dogs but also uses contexts such as Chinese dragons, hot-air balloons, butterflies and kites (Describing Butterflies, Describing Kittens, see Figures 1 and 2). These resources can be used with the whole class, to teach the importance of using precise vocabulary in a description. Students can use them independently and then have a peer review their work and give them feedback. The ARB team have selected colourful and appealing photos to accompany these tasks. If you don't like the contexts provided, you can take the concept and use it in the classroom (although you'll have to find your own photos!).

Science tasks make good use of external resources such as websites and video clips. Two examples relate to butterflies. One focuses on the life cycle of a butterfly and uses diagrams and information from the Science Learning Hub website as a source of information for answering a series of questions (Butterfly Life Cycle). The second resource utilises video footage of a butterfly emerging from a chrysalis to encourage accurate scientific observation (The monarch: chrysalis to butterfly), see Figure 3). Although aimed at Level 2 students, it can easily be used with younger students as the responses that are gathered are oral, so the task could be completed with a class, a small group or an individual. I wish I'd come across this resource last year when my Year 2 class were learning to be scientists and observing closely. Another example of using video is the Managing Fire science resource which uses a video, also from the Science Learning Hub, of two sofas burning (one with fire retardant, the other without) and asks students to observe what is happening and record these observations

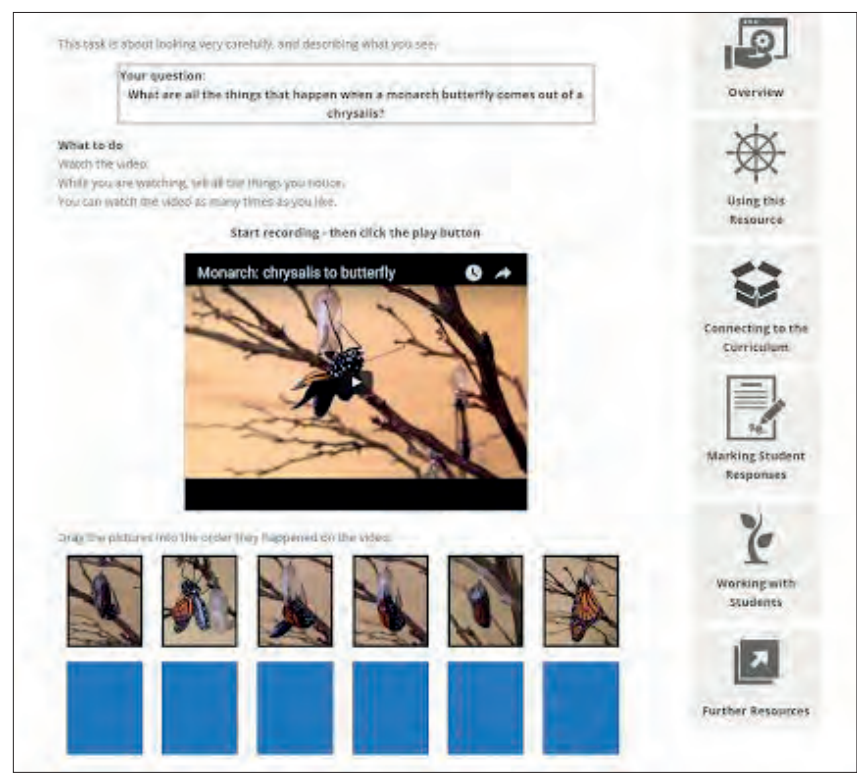

FIGURE 3. THE MONARCH: CHRYSALIS TO BUTTERFLY and make comparisons between the two. This great use of an existing online video can readily be adapted to other videos or scenarios that fit in with a classroom inquiry.

There is a range of online resources where students are asked to drag and drop pictures or numbers. The English banks have tasks which require students to put pictures from a story in order, then use these to write a narrative. "A pumpkin story", "A canoe story" and "Building a deck" are examples. Science resources use this type of task to assess student understanding of natural cycles such as "Paradise Ducks' life cycle", "Life cycle of the kakapo", "The beech forest III" and "Germinating bean seeds". For these tasks students order pictures of the various stages of a cycle then answer questions based on their responses. This type of task is also used in maths for ordering numbers- "Ordering improper and mixed fractions" (see Figure 4) and in probability to order the likelihood of events- "Black and White". Similarly, there are resources such as "Paragraphs 1" in which students highlight different sentence types within a paragraph to show their understanding of how a paragraph is constructed. No more worrying about having enough highlighters for each class member or students highlighting the incorrect part—having it all online eliminates these issues.

All in all the online platform enables a rich source of information about student understanding which can be gathered more quickly than the traditional cut and paste method AND no more sticky fingers, lost bits of paper or missing highlighters!

\section{Online feedback}

Late last year a small group of my Year 2 students trialled some interactive maths resources and loved being able to complete the tasks online and get their results in real time. All students can now complete a huge range of interactive online assessments anywhere, any time, using PCs, iPads or Chromebooks. So the ARBs can be used in classrooms where students have their own devices or ready access to computers. However, if that isn't the case in your school or your classroom yet-almost all online resources still have a print option.

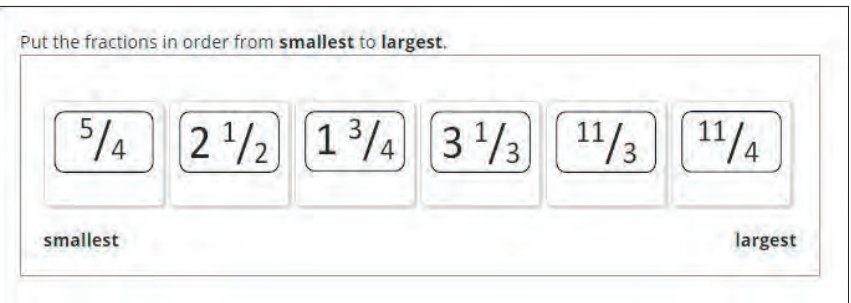

FIGURE 4. ORDERING IMPROPER AND MIXED FRACTIONS 
Giving students feedback can take time-collecting in papers, marking them, returning them as soon as possible and using the feedback to tailor the next lesson or lessons. Some types of questions within the new online resources are marked automatically, and students can instantly see their results. Currently these results can be downloaded or emailed as PDFs. One of my students, upon seeing his results, immediately wanted to go back and re-do the questions he had got wrong. What a powerful tool for students and teachers alike. (One day teachers will be able to access these results as soon as a student has completed a task.) Students can identify their own areas of strength and weakness while teachers can see what areas an individual or group need support with and set up their learning for the next session or lesson. Common misconceptions are easier to find and can be addressed before they become embedded.

If you haven't checked out the ARBs before or, like me, haven't discovered all the recent changes, then find some time to look around: http://arbs.nzcer.org. $\mathrm{nz} /$ And, remember, there are always new resources and information being added regularly. I hope you find something you like.

\section{References}

Joyce, C., \& Fisher, J. (2014), Assessment for learning, online tasks, and the new Assessment Resource Banks. set: Research Information for Teachers, 2, 51-53.

Ministry of Education. (2007). The New Zealand curriculum. Wellington: Learning Media.

Teresa Maguire is a researcher/resource developer at the New Zealand Council for Educational Research. Until recently she was a full-time primary school teacher and team leader with school-wide maths and ICT responsibilities. She is currently converting pencil and paper resources to interactive resources for the maths and English banks and is developing maths resources.

Email: teresa.maguire@nzcer.org.nz 